\title{
Applying "Four Together" Principle to minority and Han Students in Undergraduate Innovation and Entrepreneurship Training Program
}

\author{
Dayong Huo \\ Kashgar University, Kashgar 844006, China \\ hnnyhdy@163.com
}

\begin{abstract}
Keywords: Innovation and entrepreneurship; Training program; Minorities and han university students; Karshgar university; Four together
\end{abstract}

\begin{abstract}
Take students major in electrical engineering and automation in Karshgar university for example, this paper introduces the educational practice of applying "Four Together" principle to minority and Han students in undergraduate innovation and entrepreneurship training program. By means of the comparison of the sample group and the control group, this paper analyzes the influences in the belongingness of emotion, culture, mental-trust and behavior-trust by the entrance of undergraduate innovation and entrepreneurship training program. Following conclusions are obtained, students from different cultural background work together as groups in the undergraduate innovation and entrepreneurship training program, as a result, this combination effectively strengthens the communication and understanding of students from different cultural backgrounds, reinforces the peer effects and is extremely helpful in uniting nations thus achieve harmonious society.

University period is important to one's life. In this period, both educational and non-educational experiences are crucial to build students' world view and life view, thus influence the development of students' career lives. In this case, the "Four Togethers" principle is suggested: Undergraduates should learn together, play together (including sport events, culture events, party events, and social events), live together (such as having food together, sleeping together, etc.), and grow up together. The "Four Togethers" principle shall work as an invisible "bridge" that links students. In this way, friendly and harmonious campus can be built.
\end{abstract}

The "Four Together" principle is effective because it creates students' belongingness. In this method, teenagers gain deep understand of each other when living together, generate belongingness of living. Also, while communicating, they gain belongingness of emotion, culture, and life value. As a result, for every student, the belongingness builds mental-trust in their minds and behavior-trust in their bodies. Furthermore, the harmony of each nation can be achieved.

China lives Han people and minority people. The culture differences (including language, thought and behavior difference) among them should be carefully treated, especially in the autonomous regions where most minorities live, such as Xinjiang, Xizang and Qinghai. For universities in Xinjiang Uygur Autonomous Region, Han students and minority students, mostly are Uygur students, studied together. To achieve effective communication between minority students and Han students, it is crucial to apply "Four Together" principle. For another concern, to advocate "Four Togethers" principle to teenagers, educational and technical events favored by them should be held.

Currently, the "Undergraduate Student Innovation and Entrepreneurship Training Program" is strongly promoted by autonomous region government. This program, on the one hand, aims to motivate students in inventing and entrepreneurships, raising their abilities in both researching and working. On the other hand, the program benefits companies by bringing them well-educated undergraduates. This program can "promote deep educational reformation of colleges in Xinjiang Uygur Autonomous Region, and strengthen the practice-based education"12. Throughout the daily lives of students, this program covers their campus lives and extends to their career times 2 . In this training, undergraduates are encouraged to work on research topics as groups, and they are also suggested to strengthen their abilities on "self-learning, group-working, organizing, and implementing" 3 . In our research, we bring new ideas to this program that guiding both minority and 
Han students to work together as groups. In this way, they may affect each other with the help of "Four Together" principle.

Experts in and out of Xinjiang have worked on the methods to achieve the belongingness between minority students and Han students. Article 4 to 8 consider that their collaboration in study and contact in life are fundamental to create belongingness; Article 3, 8 and 10 illustrate the "undergraduate innovation and entrepreneurship training program" is helpful to build trust, collaboration and mutual-inspiration in each group formed by the program; Article 1 and 2 emphasized, in the present and future, the "undergraduate innovation and entrepreneurship training program" is the main part of college practice-based education, for both the country and the autonomous region, respectively; And article 1 and 2 also underlined that in long-range perspective, the "undergraduate innovation and entrepreneurship training program" will be highlyrecommended and implement in large scale.

In this work, we applied the training program to undergraduates, formed research teams contains both minorities and majorities. And the groups are suggested to be formed with students under similar majors and interests. In the researching process, the "Four Togethers" principle was proposed. The mental-trust and behavior-trust among minority and majority students were finally achieved upon suitable method and previous research experiences.

So far, in Kashgar University, 104 undergraduate innovation and entrepreneurship training projects above school-level are preceded. All the projects are operated by minority-majority-mixed teams, containing 425 undergraduates in total. As for electrical engineering and automation major, 48 students joined the program and hold 9 projects, including 2 national-level projects, 4 provincial-level projects and 3 school-level projects. Of these 9 projects, 2 are cultural and artistic projects, 3 are scientific projects, and 2 are scientific-service projects. In the process of these trainings, the projects provide chances for students to get familiar with each other thus build friendships. Students' performances before and after the program are compared. Typically, the results collected from two groups are listed.

Project 1: Provincial-level projects "Research on cultures of food and clothes in the epic Manas" is chosen, where Manas is an epic of Khalkhas nation. This project aims to compare the traditional cultures recorded in Manas with modern cultures, and inheriting and developing traditional culture. The research method based on field investigation and document retrieval. The project is proposed by Electrical Engineering and Automation sophomores of two classes, taking effect from January 2016 to May 2017. The research group consists of 5 Khalkhas students, 4 Han students, and 2 Uygur students, all of which were growing in their national settlements. To compare, we use their classmates that did not attend the project as control group, including 12 minority students and 10 Han students. After one-year of working on the project, surveys and tests are made to show the effect. The results are as follows:

(1) For the 7 minority students, their capability of Chinese raised $21 \%$, which has 7 percentiles higher than control group, according to paper-based reading tests.

(2) Based on questionnaire surveys, for each of the 7 minority students, the number of their Han friends increase to $10+$. In control group, only $41.7 \%$ students have $10+$ Han friends of the same age.

(3) Due to paper-based tests on Kashgar culture, all the 4 Han students get grade exceed 70, with average grade of 85.3 while the average grade of control group is 62 .

(4) Based on questionnaire surveys, for each of the 4 Han students, the number of their Uygur and Khalkhas friends increase to $15+$. In control group, only $60 \%$ students have $15+$ Uygur and Khalkhas friends.

Project 2 and 3: Provincial-level projects "Investigation and design of rural electrical safety in Yengisar county" and national project "Investigation and design of electrical safety in Kashgar middle-western Asia international trade market" are chosen. The two projects are based on their advisor's research project "Carrying out electrical-safety lectures in four southern-Xinjiang counties". The two projects contain electrical-safety survey, pop-science materials compilation, pop-science preach, and providing technical service. The projects are proposed by Electrical 
Engineering and Automation juniors in two classes, taking effect from January 2016 to May 2017. The research groups consist of 8 Han students, and 11 Uygur students, all of which were growing in the national settlements. To compare, we use their classmates that did not attend the project as control group, including 12 minority students and 10 Han students. After one-year of working on the project, surveys and tests are made to show the effect. The results are as follows:

(1) For the 11 minority students, their capability of Chinese raised $9.11 \%$, which has 4.09 percentiles higher than control group, according to paper-based reading tests.

(2) Based on questionnaire surveys, for each of the 11 minority students, the number of their Han friends increase to $12+$. In control group, only $83.3 \%$ students have $12+$ Han friends of the same age.

(3) Due to paper-based tests on Kashgar culture, all the 8 Han students get grade exceed 85, with average grade of 90.2 while the average grade of control group is 81.5.

(4) Based on questionnaire surveys, for each of the 8 Han students, the number of their Uygur and Khalkhas friends increase to $15+$. In control group, only $80 \%$ students have $15+$ Uygur and Khalkhas friends.

Project 4: Provincial-level projects "Electric car accidentally touch the switch" is chosen. The research method based on circuit design, physical production. The project is proposed by Electrical Engineering and Automation sophomores of two classes, taking effect from January 2016 to May 2017. The research group consists of 6 Han students, and 4 Uygur students, all of which were growing in their national settlements. To compare, we use their classmates that did not attend the project as control group, including 10minority students and 10 Han students. After one-year of working on the project, surveys and tests are made to show the effect. The results are as follows:

(1) For the 4 minority students, their capability of Chinese raised 19\%, which has 6 percentiles higher than control group, according to paper-based reading tests.

(2) Based on questionnaire surveys, for each of the 4 minority students, the number of their Han friends increase to $10+$. In control group, only $50 \%$ students have $10+$ Han friends of the same age.

(3) Due to paper-based tests on Kashgar culture, all the 6 Han students get grade exceed 70, with average grade of 85.3 while the average grade of control group is 68 .

(4) Based on questionnaire surveys, for each of the 6 Han students, the number of their Uygur and Khalkhas friends increase to $15+$. In control group, only $70 \%$ students have $15+$ Uygur and Khalkhas friends.

According to the data, we can also obtain that, as time goes on, the connection among group members are strengthened, which prove the efficiency of "Four Together" principle. Also, better students' performances are achieved by using the innovation and entrepreneurship program as carrier of the principle. To conclude, we combine the training program with the "Four Together" principle. In this process students from different cultural background work together as groups, understanding and affecting each other. This combination effectively strengthens the connection of people from different cultural background, which is extremely helpful in uniting nations thus achieve harmonious society.

\section{Acknowledgement}

This research is supported by "Practicing of 'Four Together' Principle by Minority-Han Student Innovation and Entrepreneurship Training Program" (16SZJY21), the education department of Xinjiang Uygur Autonomous Region.

\section{References}

[1] National Undergraduate Innovation and Entrepreneurship Training Program expert working group. National college students' innovative entrepreneurial training program manual work [D] (In Chinese). Ministry of education of the People's Republic of China.2012.11

[2] Undergraduate Innovation and Entrepreneurship Training Program and implementation plan 
of the xinjiang uygur autonomous region [M] (In Chinese). The education department of xinjiang uygur autonomous region. 2015.03

[3] B. Yu and X.B. Yan: Exploration and practice on project management of "Undergraduate Innovation and Entrepreneurship Training Program" [J] (In Chinese). Experimental Technology and Management .Vol.32 (2015) No.9, pp30-33

[4] J. Zhang, X.P. Wu and X.A. Wang: Minorities and Han theory of people agree with each other depending on of worshiping the university students' humanistic education in xinjiang [J]. Tribune of Social Sciences in Xinjiang(In Chinese).Vol.26 (2015) No.2, pp100-104

[5] Zuliyati Simayi: Research on the Educational Model Transformation from "Ethnic Minorities and Han Double-track System" to "The Integration of Ethnic Minorities and Han" in Xinjiang Colleges and Universities [J] (In Chinese). N. W Journal of Ethnology. Vol.29 (2015) No.3, pp48-59

[6] J.J. Gu, F.L. Li and H.Y. Dong: Under the theory of intergroup contact Angle of Minorities and Han University students room together [J] (In Chinese). The Party Building and Ideological Education in Schools. Vol.30 (2014) No.4, pp44-51

[7] H. Wang and R. Ma: Empirical Research on the Impact of Cheerleading Training on Mental and Physical Quality and the Degree of Identification of College Students of Ethnic Minorities and Han Majority [J] (In Chinese). China School Physical Education.Vol.2 (2015) No.8, pp80-83

[8] G.P. Xie, L.L. Sun and C.F. Jiang: Current Situation Survey and Countermeasure Discussion on Identifying Nationality for Minority and Han College Students in Universities in Xinjiang [J] (In Chinese ) . Journal of Tarim University.Vol.23 (2011) No.2, pp53-59

[9] Y.D. Liu, L.Y. Ren and L.Y. Feng: Understanding of the National Undergraduate Innovation and Entrepreneurship Training Program [J] (In Chinese). Journal of Inner Mongolia Normal University (Educational Science).Vol.27 (2014) No.1, pp7-10

[10] J.W. Zhang, Z. Zhang, X.M. Chang, R. Zhang and Y.Q. Cheng: Exploration and Practice of the Effectiveness of Process Management in Local College Students' Innovative Training Program [J] (In Chinese). Research in Higher Education of Engineering. Vol.32 (2014) No.5, pp135-138

[11]X.H Chen, X Yang: Fourteen basic questions in the development of applied undergraduate colleges and universities [J] (In Chinese). China University Teaching. Vol.35 (2013) No.1, pp.281-304.

[12]Z.J Wu, C.L Huang: The Concept and Cultivation of Applied Talents [J] (In Chinese) . Research in Higher Education of Engineering. Vol.32 (2014) No.2, pp.66-70.

[13] C.Y Hu, X.Y Liu and H.Y Jin: Research on applied undergraduate colleges and universities graduates employment ability training path [J] (In Chinese). Journal of Changchun University of Science and Technology (Social Sciences Edition). Vol.27(2014)No.6, pp.147-150.

[14]B. Ling: Discussion on Improvement of Graduates Employability for Application-oriented University [J] (In Chinese). Journal of Hefei Normal University. Vol.31(2013)No.6, pp.130-132. 